\title{
DISSERTAÇÕES DE MESTRADO ATRELADAS A PROJETOS DE EXTENSÃO: PREMISSAS AO TRIPÉ ACADÊMICO
}

\author{
JULIANA DE PAULA FIGUEIREDO ${ }^{1}$ \\ ORCID: https://orcid.org/0000-0001-8477-465X \\ DALIANA STEPHANIE LECUONA ${ }^{2}$ \\ ORCID: https://orcid.org/0000-0002-4556-8252 \\ ALEXANDRA FOLLE ${ }^{3}$ \\ ORCID: https://orcid.org/0000-0001-8972-6075 \\ GELCEMAR OLIVEIRA FARIAS 4 \\ ORCID: https://orcid.org/0000-0003-3552-3437 \\ ALCYANE MARINHO 5 \\ ORCID: https://orcid.org/0000-0002-2313-4031
}

\begin{abstract}
RESUMO: O objetivo deste artigo é apresentar uma investigação sobre o envolvimento de estudantes de pós-graduação em Educação Física, da Universidade do Estado de Santa Catarina (UDESC), em projetos de extensão na construção de suas dissertações de mestrado. A metodologia empregada foi a da pesquisa aplicada, a qual possui um caráter descritivo, com análise qualitativa dos dados. Participaram deste estudo sete mestres em Educação Física, com idade de $28 \pm$ 7,07 anos. Utilizou-se um questionário on-line, o qual continha os dados de caracterização dos participantes e dez perguntas abertas. Os dados foram analisados por meio da Técnica de Análise de Conteúdo. Como resultado, identificou-se um engajamento dos investigados em projetos de extensão que vinha sendo realizado desde a graduação, e isso os motivou a dar continuidade nesse ato também durante a pós-graduação. Além disso, os mestres investigados identificaram diversos benefícios em atrelar a dissertação à extensão. Com isso, acredita-se na potencialidade de pesquisas relacionadas à extensão e no incentivo a esses tipos de pesquisa, pois eles poderiam proporcionar uma retroalimentação, garantindo intervenções qualificadas à comunidade.
\end{abstract}

Palavras-chave: extensão universitária, pós-graduação, dissertação, Educação Física.

\section{MASTER'S DEGREE DISSERTATIONS LINKED TO EXTENSION PROJECTS: ASSUMPTIONS FOR THE ACADEMIC TRIPOD}

\begin{abstract}
This article aim is to present a research about the involvement of postgraduation students in Physical Education, from the University of the State of Santa Catarina (UDESC), in extension projects in the development of their Master's degree dissertation. The methodology employed was the applied

\footnotetext{
${ }^{1}$ Universidade do Estado de Santa Catarina (UDESC). Florianópolis, SC, Brasil. <julianapfig@hotmail.com>

${ }^{2}$ Universidade do Estado de Santa Catarina (UDESC). Florianópolis, SC, Brasil.<dalianalecuona@gmail.com>

${ }^{3}$ Universidade do Estado de Santa Catarina (UDESC). Florianópolis, SC, Brasil.<afolle_12@hotmail.com>

${ }^{4}$ Universidade do Estado de Santa Catarina (UDESC). Florianópolis, SC, Brasil. < fariasgel@hotmail.com>

${ }^{5}$ Universidade do Estado de Santa Catarina (UDESC). Florianópolis, SC, Brasil.<alcyane.marinho@hotmail.com>
} 
research, which has a descriptive character, with qualitative analysis of the data. Seven Masters of Physical Education took part in this study, with the age of $28 \pm 7,07$ years old. An online questionnaire was employed, which hold in data of characterization of the participants and ten open questions as well. The data were analyzed by the Technic of Content Analysis. As a result, the attachment of the participants in the extension projects that had been carried out since the graduation was identified, and this has motivated them to maintain this attachment also during the postgraduation. Furthermore, the investigated Masters have identified many benefits in linking their dissertation to the extension. In conclusion, we believe in the potentiality of the researches related to extension and in motivating these kind of studies, once they could provide a feedback to academic research, and assure qualified interventions to the community.

Keywords: university extension, postgraduation, dissertation, Physical Education.

\section{TESIS DE MAESTRÍA ATRAILLADAS A LOS PROYECTOS DE EXTENSIÓN: PREMISAS AL TRÍPODE ACADÉMICO}

RESUMEN: El objetivo de este artículo es presentar una investigación acerca del involucro de estudiantes de postgrado en Educación Física, de la Universidade do Estado de Santa Catarina (UDESC), en proyectos de extensión en la construcción de sus tesis de maestría. La metodología empleada ha sido la de investigación aplicada, que posee un carácter descriptivo, con análisis cualitativa de los datos. Han participado de este estudio siete Mestres en Educación Física, con edad variante entre 28 y 7,07 años. Se ha utilizado una encuesta en línea, que contenía los datos de caracterización de los participantes y diez preguntas abiertas. Los datos han sido analizados por medio de la Técnica de Análisis de Contenido. Como resultado, se ha identificado un compromiso de los investigados con los proyectos de extensión que estaban siendo realizados desde el grado, y eso les ha motivado a dar continuidad a este acto también durante el postgrado. Además, los Mestres investigados han identificado varios beneficios en atraillar la tesis a la extensión. Con eso, se cree en la potencialidad de las investigaciones relacionadas a la extensión y en el incentivo a esos tipos de investigación, puesto que podrían ellos proporcionar una retroalimentación, garantizando intervenciones cualificadas a la comunidad.

Palabras clave: extensión universitaria, postgrado, tesis, Educación Física. 


\section{INTRODUÇÃO}

A pós-graduação é estruturada nos níveis lato sensu e stricto sensu. Neste estudo, focaliza-se o âmbito da pós-graduação stricto sensu, sendo definido como a constituição de cursos sistematicamente organizados que dão continuidade à formação do Ensino Superior (CONSELHO FEDERAL DE EDUCAÇÃO, 1965), o qual envolve o doutorado, o mestrado acadêmico e o mestrado profissional.

No contexto brasileiro, o mestrado acadêmico, foco deste estudo, tem como premissa formar pesquisadores, com a expectativa de que, após a conclusão do curso, o aluno dê prosseguimento ao doutorado. Esse tipo de mestrado constitui-se um conjunto de atividades de cunho acadêmico, tendo como requisito final a apresentação de uma dissertação, ou outro tipo de trabalho de conclusão de curso, conforme exigências internas do programa, devendo ser compatível com a área de conhecimento em que se insere (MACHADO; SANTOS; QUARESMA, 2014).

Entretanto, Moreira (2004) levantou a discussão de que os mestrados acadêmicos não coadunam com as reais necessidades dos professores, ao passo que os mestrados profissionais, em sua opinião, buscam, a todo momento, promover a formação profissional atrelada ao que se propõe, associando, ainda, a pesquisa à área de atuação. Essa reflexão ainda chama a atenção para a necessidade de um maior estreitamento do curso de mestrado, durante a formação do aluno, com o público e a área a serem investigados, o que poderia ser suprido pelo contato do mestrando com projetos de extensão.

De acordo com Lei de Diretrizes e Bases da Educação Nacional, Lei no 9.394, Artigo 43, Parágrafo III, uma das finalidades do ensino superior é "incentivar o trabalho de pesquisa e investigação científica, visando o desenvolvimento da ciência e da tecnologia e da criação e difusão da cultura, e, desse modo, desenvolver o entendimento do homem e do meio em que vive" (BRASIL, [2018]). Nesse documento, pode-se perceber o ensejo da articulação entre pesquisa e extensão.

Nessa perspectiva, alguns estudos apontam para as contribuições do envolvimento do estudante com projetos de extensão e iniciação científica ainda no Ensino Médio (HECK et al., 2012; KREMER; WELTER; GROSSI, 2014). Esse tem sido um investimento da Educação realizado por intermédio da parceria entre universidades e escolas públicas, no intuito de introduzir os alunos do Ensino Médio no âmbito da pesquisa, ofertando, inclusive, bolsas de estudos por meio do Programa Institucional de Bolsas de Iniciação Científica para o Ensino Médio (PIBIC-EM). Ao passarem para o nível da graduação, Manchur, Suriani e Cunha (2013) salientam, como benefícios do envolvimento dos alunos de licenciatura com projetos de extensão, a familiaridade desses alunos com a prática docente, de modo a potencializar sua formação acadêmica por meio do desenvolvimento de metodologias de ensino.

Em um contexto mais amplo, Mazo et al. (2013) trazem as peculiaridades de um projeto de extensão desenvolvido, voltado ao público idoso, no qual foram realizadas ações que envolviam tanto os cursos de graduação quanto os de pós-graduação (mestrado e doutorado), ambos em Educação Física, de modo a capacitar, constantemente, profissionais para atuarem na área e a envolver, de maneira 
integrada, a comunidade acadêmica e as entidades governamentais e não governamentais, proporcionando benefícios aos diferentes atores envolvidos: idosos, alunos e a própria Universidade. Os autores ainda focalizam a articulação entre os três pilares da universidade, quais sejam: ensino, pesquisa e extensão, visando promover ressonâncias interdisciplinares e integralmente formativas.

Nesse cenário, ao se buscar estabelecer relações da pós-graduação com ações de extensão universitária, foram observadas algumas lacunas na produção do conhecimento, uma vez que os estudos publicados visam apresentar as contribuições da extensão universitária para a comunidade (FERNANDES et al., 2012; RODRIGUES et al., 2013), ou para a formação de profissionais (LIMA, 2015; KOCHHANN, 2017). Tais focos, igualmente, podem ser visualizados na especificidade das publicações da área da Educação Física (BARRAGÁN et al., 2016; HIRANA et al., 2016), na qual também não se encontrou divulgação de pesquisas que visassem a construção de dissertações vinculadas a projetos extensionistas.

Nesse sentido, o estudo aqui apresentado teve como objetivo investigar o envolvimento de estudantes de pós-graduação em Educação Física, da Universidade do Estado de Santa Catarina (UDESC), em projetos de extensão na construção de suas dissertações de mestrado.

\section{PROCEDIMENTOS METODOLÓGICOS}

Esta pesquisa caracteriza-se como aplicada, de caráter descritivo, com análise qualitativa das informações. Participaram voluntariamente deste estudo sete mestres em Educação Física da Universidade do Estado de Santa Catarina, os quais construíram suas dissertações diretamente relacionadas a projetos de extensão de seus respectivos laboratórios. O presente estudo foi aprovado pelo Comitê de Ética em Pesquisa com Seres Humanos da UDESC, sob o parecer nº 2.515.788, de 21 de dezembro de 2017. Ademais, foi obtido financiamento por parte da Fundação de Amparo à Pesquisa e Inovação do Estado de Santa Catarina (FAPESC).

Para a inclusão dos participantes na pesquisa, foram utilizados os seguintes critérios: ter realizado o mestrado na área de Educação Física; ter defendido a dissertação nos últimos três anos, devido à atualização dos dados e aproximação cronológica com os resultados; ter estabelecido vínculo direto com o laboratório no qual o trabalho foi realizado; ter participado de atividades de extensão durante o período de construção da dissertação. Os critérios de exclusão delimitaram-se a: não apresentar relação direta com a extensão durante o mestrado; ter realizado extensão em laboratório diferente ao do orientador da dissertação.

Foram convidados a participarem da pesquisa sete mestres, devido à facilidade de acesso a eles, bem como à representatividade dos laboratórios, no contexto extensionista da universidade investigada, aos quais estavam vinculados no período do mestrado. Além disso, foi observada a 
repercussão dos desdobramentos de suas dissertações. Ressalta-se que os nomes desses participantes foram substituídos por nomes fictícios, a fim de preservar suas identidades.

Para a coleta dos dados, foi utilizado um questionário on-line, autoaplicável, criado a partir do recurso digital Google Docs e enviado por e-mail aos participantes. O questionário foi dividido em duas partes: a primeira continha dados de caracterização dos participantes (nome, idade, laboratório vinculado durante o mestrado e projeto de extensão vinculado); e a segunda parte continha dez questões abertas referentes à realização da dissertação, a respeito das ressonâncias existentes entre o universo da extensão e a produção de dissertações de mestrado (estas versavam sobre: as experiências durante a graduação e a pós-graduação envolvendo a extensão; os motivos para o desenvolvimento da dissertação atrelada a um projeto de extensão; as características do projeto de extensão ao qual o mestrando era vinculado; a percepção sobre os benefícios relacionados ao trabalho concomitante com as atividades de extensão durante o mestrado; os benefícios dos projetos de extensão para as pesquisas de pós-graduação e viceversa; a visão das dificuldades e limitações e da importância de se trabalhar o tripé acadêmico; e sugestões para um melhor funcionamento da relação entre extensão e pós-graduação).

Esse instrumento de estudo foi validado por três doutores da área de Educação Física que tinham aproximação com as temáticas da pesquisa, os quais verificaram as questões acerca do conteúdo e da clareza envolvendo as perguntas do questionário.

A coleta dos dados foi realizada de forma on-line, no mês de novembro de 2016. Embora exista um Banco de Teses e Dissertações defendidas na página oficial do programa de pós-graduação investigado, os títulos em si e/ou os resumos desses trabalhos não mencionavam diretamente a relação da dissertação com o envolvimento em projetos de extensão. Assim, optou-se por realizar a busca pelos mestres que atendiam aos critérios de inclusão, com consulta direta aos orientadores e aos próprios pósgraduados, tornando esse levantamento mais efetivo.

Em seguida, fez-se contato com os mestres que desenvolveram suas dissertações diretamente relacionadas às propostas de extensão de algum laboratório, por meio de ligações e e-mails, objetivando explicar a pesquisa e realizar o convite para participar do estudo. Todo o processo da investigação foi explicado aos participantes detalhadamente, com informação sobre sua não identificação e a garantia de sua desistência, a qualquer momento, da pesquisa. Estando os mestres de acordo com os termos da pesquisa, assinaram virtualmente o Termo de Consentimento Livre e Esclarecido (TCLE). Os questionários e o TCLE foram estruturados utilizando-se o Google Docs, e, assim, os participantes puderam enviar suas respostas por meio do link que foi enviado para seus e-mails pessoais. Esse recurso tem sido comumente empregado em pesquisas acadêmicas de diferentes áreas do conhecimento (ANJOS; CARIO; FIATES, 2014; FERREIRA; SANCHES, 2013; VIVIURKA; PORTO ALEGRE, 2013), devido à facilidade de uso e melhor acessibilidade.

Os dados coletados foram organizados por intermédio do recurso digital Google Docs, Versão 2016, e analisados por meio de elementos da Técnica de Análise de Conteúdo, seguindo as orientações 
de Bardin (2009). Foram estabelecidas duas categorias de análise: 1) ressonâncias da participação em projetos de extensão na formação de mestres em Educação Física; 2) pontes entre extensão e pósgraduação.

\section{RESULTADOS E DISCUSSÃO}

Participaram deste estudo quatro mulheres e três homens, com idade de $28 \pm 7,07$ anos. Tal característica relacionada à faixa etária pode ter reflexo na atual tendência dos estudantes em iniciarem a pós-graduação logo após a conclusão do curso de graduação, o que requer um olhar atento aos egressos universitários. O interesse pela formação continuada pode ser confirmado no estudo de Salles, Farias e Nascimento (2015), tendo eles verificado que, do total de 34 bacharéis e 29 licenciados da Universidade Federal de Santa Catarina (UFSC), 79\% e 83\%, respectivamente, demonstraram interesse em realizar algum tipo de atividade com esse fim, sendo caracterizado, principalmente, sob a forma de cursos de pósgraduação lato sensu e/ou stricto sensu.

Corroborando esse achado, em uma pesquisa realizada com egressos da Universidade Federal de São Carlos (UFSCar), do curso de Educação Física, apontou-se que 64,6\% dos profissionais investigados deram continuidade à formação profissional, seja por meio de cursos de especialização, seja de mestrado (RAMOS et al., 2008). Nessa perspectiva, Cirani, Campanario e Silva (2015) apontam que um dos principais motivos para a expansão dos cursos de pós-graduação no Brasil tem reflexo, justamente, no maior interesse da sociedade em elevar seu nível de formação, a fim de atender às exigências do mercado.

Em relação aos projetos de extensão nos quais os mestres investigados participavam, foi possível verificar que dois eram relacionados a idosos, sendo um referente à musculação e o outro ao exercício físico para mulheres com incontinência urinária. Outros dois projetos tratavam-se de reabilitação cardíaca, nos quais um deles abrangia a reabilitação cardiopulmonar e metabólica para diferentes faixas etárias. O quinto projeto envolvia a musculação para pessoas com síndrome de fibromialgia, o qual relacionava questões da psicologia do exercício com os entraves da doença. O sexto projeto contemplava a dança para pessoas com doença de Parkinson. Por fim, o sétimo projeto que compõe a amostra deste estudo versava sobre o exercício físico para mulheres em tratamento do câncer de mama.

\section{Ressonâncias da participação em projetos de extensão na formação de mestres em Educação} Física

Considerando a importância do envolvimento dos alunos de graduação nas diversas esferas da universidade, foi questionado aos mestres a ligação deles com projetos de extensão durante sua 
formação inicial. Os sete participantes investigados afirmaram ter se envolvido com atividade extensionista, sendo que um deles relatou tê-la iniciado logo no segundo semestre do curso.

O envolvimento dos participantes deste estudo deu-se no âmbito extensionista, durante a graduação, de diversas maneiras, tais como: contribuição na elaboração do projeto de extensão; supervisão dos participantes; atuação em eventos; orientação dos bolsistas vinculados ao projeto de extensão; auxílio no planejamento das atividades; intervenção durante as ações; e colaboração nas avaliações neuropsicomotoras dos integrantes do projeto. Além disso, constatou-se a transição da condição de bolsistas de extensão para bolsistas de iniciação científica durante a formação inicial, reforçando a importância da indissociação entre os pilares da universidade, como pode ser verificado na fala de um dos investigados: "Foram dois anos trabalhando [...], um como bolsista de extensão e outro como bolsista de iniciação à pesquisa, a qual estava relacionada à extensão" (Tiago).

Tais ações realizadas pelos antigos bolsistas de extensão, atuais mestres, também podem ser verificadas no estudo de Crestani et al. (2004), os quais discutem as atividades de bolsistas de extensão durante a participação destes em um projeto focalizado na promoção de saúde a pessoas ostomizadas ${ }^{6}$. Os autores relatam que, durante o período em que os bolsistas estiveram participando desse projeto, estes acompanharam o grupo de ostomizados, participaram das intervenções propostas por profissionais mais qualificados e apresentaram trabalhos de pesquisa em eventos científicos, de maneira a fortalecer a ponte ensino-pesquisa-extensão, enfatizando a pluralidade de funções do bolsista de extensão e sua constante troca de saberes com as demais vertentes científicas, como o ensino e a pesquisa.

Ao se focalizar a pós-graduação, especificamente para o contexto ora investigado, considerando que o curso de Educação Física e os laboratórios da UDESC apresentam um campo fértil em opções de projetos de extensão e que os mestres investigados possuíam experiências prévias com tais projetos, durante sua formação inicial, foi observado que os investigados evidenciaram uma ampliação de suas responsabilidades, durante a realização do mestrado. Os mestres investigados, por suas vivências formativas e profissionais anteriores e suas atuações em projetos de extensão, podem estar se considerando aptos a compartilharem seus conhecimentos com os que adentram o contexto da graduação, durante o período em que estão realizando a pós-graduação, assim como podem se perceber com competência para assumir maiores responsabilidades durante as intervenções, fazendo com que, consequentemente, suas funções sejam ampliadas.

Diante desse aspecto, os investigados ressaltaram, como suas principais funções: a aplicação de atividades práticas, como aulas de dança e musculação (4); a supervisão de bolsistas de graduação (2); a organização e a supervisão do proposto pelo projeto de extensão (como aplicação de atividade física a

\footnotetext{
${ }^{6}$ Pessoa ostomizada "é aquela que precisou passar por uma intervenção cirúrgica para fazer no corpo uma abertura ou caminho alternativo de comunicação com o meio exterior, para a saída de fezes ou urina, assim como auxiliar na respiração ou na alimentação. Essa abertura chama-se estoma. [...]”. Disponível em: http://www.oncoguia.org.br/conteudo/ostomizados/1853/15/. Acesso em: 19 nov. 2020.
} 
grupos de risco) (2); a coordenação das etapas do projeto (1); a avaliação e a reavaliação (1); o planejamento das aulas e o acompanhamento dos participantes durante as aulas (1), a divulgação do projeto (1); o recrutamento de pacientes (1); e a análise dos dados (1). Vale enfatizar que, por se tratar de uma questão aberta, os participantes puderam apresentar mais de uma resposta.

Nesse sentido, destaca-se que o envolvimento com projetos de extensão, para além do desenvolvimento de pesquisas e da elaboração de dissertações, requer maior dedicação do pósgraduando, se comparado com aqueles que não, necessariamente, atrelam suas pesquisas de mestrado a tais projetos. Assim, pode-se observar aspectos como a supervisão de bolsistas e a responsabilidade técnica pelo projeto de extensão, citados pelos mestres investigados, como demandas possíveis para um profissional formado e que está na pós-graduação, mantendo e aperfeiçoando o vínculo com a área acadêmica. Indubitavelmente, as situações elencadas nas respostas dos investigados impulsionam as pesquisas sobre a extensão universitária, fomentando outras perspectivas acerca desse contexto.

Por meio da comparação das funções do bolsista de extensão durante a graduação e no período da pós-graduação, é possível verificar que o aumento das responsabilidades vai ao encontro do que presumem as atividades de extensão. De acordo com o exposto no I Encontro de pró-reitores de extensão das universidades públicas brasileiras (BRASIL, 1987), a extensão busca proporcionar ao aluno que participa de seus programas aprimoramento e desenvolvimento técnico-científico por meio do contato com a realidade social, viabilizando a relação entre a universidade e a sociedade, o que possibilitará ao profissional formado um conhecimento maior a respeito da realidade na qual atua, podendo planejar, conduzir e avaliar o que se propõe.

Os principais motivos para o desenvolvimento da dissertação atrelada a um projeto de extensão, por parte dos investigados, são: 1) envolvimento em projeto extensionista na graduação, motivando a continuidade durante a pós-graduação, bem como o vínculo estabelecido entre a extensão e a pesquisa no laboratório do qual fizeram parte; 2) necessidade de retorno social por intermédio da pesquisa, sendo este justificado por um mestre; 3) visibilidade do projeto e do grande público atendido, facilitando a coleta de dados e o contato com os participantes de seus estudos, fomentando, assim, o desenvolvimento de pesquisas científicas com o público-alvo; 4) necessidade de obter participantes para a amostra de seus estudos, motivando a elaboração de um novo projeto de extensão para atender tal demanda e, concomitantemente, oferecer uma nova atividade à comunidade; e 5) escolha do próprio orientador para realizar a condução do mestrado com base em ações de extensão.

O primeiro aspecto apresentado por um dos participantes desta pesquisa demonstra a importância em refletir que, comumente, o foco, durante a graduação, é destinado ao ensino e à profissionalização, ao passo que, durante a pós-graduação, ele é direcionado à pesquisa e à inovação por meio da produção e da difusão de conhecimentos (CURY, 2004). Isso pode comprometer as contribuições que tanto a pós-graduação quanto a pesquisa poderiam trazer durante a formação inicial 
nos cursos de graduação e o engajamento integral dos alunos. O desejado seria que as três dimensões ensino, pesquisa e extensão - estivessem em equilíbrio durante todas as etapas formativas.

As ressonâncias de um envolvimento precoce em atividades extensionistas e de pesquisa podem proporcionar reflexos qualitativos posteriormente. Kremer, Welter e Grossi (2014), em um relato de experiência, mostraram que alunos do Ensino Médio engajados em um projeto de extensão podiam se envolver em várias atividades, como a elaboração de cartilha educativa, de pesquisas empíricas, e a participação em eventos científicos. Ainda como desdobramento dessa experiência, entre os 10 bolsistas envolvidos, cinco ingressaram no Ensino Superior, o que pode ser considerado um reflexo desse envolvimento anterior na trajetória pessoal e profissional dos alunos. Além dessa contribuição para os alunos, o projeto possibilitou a troca de saberes na universidade, por meio da interação entre os professores, os alunos do Ensino Médio e os universitários.

O levantamento realizado por Nogueira e Canaan (2009) corrobora a relação direta de continuidade do ensino por meio das atividades extracurriculares, por verificar que a experiência da iniciação científica contribui significativamente para a carreira acadêmica do estudante de graduação, tendo em vista que os bolsistas ingressam em cursos de educação continuada em uma proporção maior do que os alunos não bolsistas, principalmente no que diz respeito aos cursos de mestrado e doutorado. Tal reflexão reitera a questão do tripé acadêmico, apresentando uma maior necessidade de estudos que demonstrem tal relação com as atividades de extensão, não somente com a pesquisa.

O Quadro 1 apresenta a estrutura, referente aos recursos humanos, das atividades de extensão nas quais os mestres investigados estavam envolvidos, bem como a configuração do planejamento do projeto de extensão.

Quadro 1 - Estrutura e planejamento dos projetos de extensão

\begin{tabular}{|l|l|l|}
\hline \multicolumn{1}{|c|}{$\begin{array}{c}\text { Nome do } \\
\text { Participante }\end{array}$} & \multicolumn{1}{c|}{$\begin{array}{c}\text { Estrutura do Projeto de } \\
\text { Extensão }\end{array}$} & \multicolumn{1}{c|}{ Planejamento } \\
\hline Ricardo & $\begin{array}{l}3 \text { alunos de graduação } \\
2 \text { alunos de pós-graduação } \\
1 \text { professor universitário }\end{array}$ & $\begin{array}{l}\text { Quando necessário, era revisado conforme os } \\
\text { resultados obtidos, e, posteriormente, formulava-se } \\
\text { uma nova estratégia de intervenção. }\end{array}$ \\
\hline Vanessa & $\begin{array}{l}2 \text { alunos de graduação } \\
2 \text { alunos de pós-graduação } \\
1 \text { profissional de Educação Física } \\
1 \text { professor universitário }\end{array}$ & $\begin{array}{l}\text { Modificado a cada 15 dias, atentando-se ao controle } \\
\text { de variáveis relacionadas ao exercício físico em } \\
\text { questão. }\end{array}$ \\
\hline Pedro & $\begin{array}{l}3 \text { alunos de graduação } \\
1 \text { aluno de pós-graduação } \\
1 \text { professor universitário }\end{array}$ & $\begin{array}{l}\text { Realizado semanalmente junto aos bolsistas de } \\
\text { extensão, a fim de adequar os aspectos técnicos } \\
\text { relacionados à modalidade oferecida pelo projeto. }\end{array}$ \\
\hline Tiago & $\begin{array}{l}10 \text { alunos de graduação } \\
\text { alunos de pós-graduação } \\
\text { profissional de Enfermagem }\end{array}$ & $\begin{array}{l}\text { Encontros periódicos para a discussão de casos } \\
\text { específicos, o planejamento das atividades, bem } \\
\text { como as modificações necessárias. }\end{array}$ \\
\hline Amanda & $\begin{array}{l}6 \text { alunos de graduação } \\
2 \text { alunos de pós-graduação }\end{array}$ & $\begin{array}{l}\text { Realizado semestralmente, havendo uma coleta de } \\
\text { dados no início do ano e outra ao final do ano, e, a }\end{array}$ \\
\hline
\end{tabular}




\begin{tabular}{|c|c|c|}
\hline $\begin{array}{l}\text { Nome do } \\
\text { Participante }\end{array}$ & $\begin{array}{l}\text { Estrutura do Projeto de } \\
\text { Extensão }\end{array}$ & Planejamento \\
\hline & $\begin{array}{l}1 \text { profissional de Educação Física } \\
1 \text { professor universitário }\end{array}$ & $\begin{array}{l}\text { cada final de semestre, era realizada uma } \\
\text { confraternização com os participantes. }\end{array}$ \\
\hline Carolina & $\begin{array}{l}1 \text { aluno de graduação } \\
2 \text { alunos de pós-graduação } \\
1 \text { professor universitário }\end{array}$ & $\begin{array}{l}\text { Elaboração de um protocolo de exercícios físicos a } \\
\text { ser seguido, o qual era aplicado conforme o } \\
\text { planejamento dos treinos. }\end{array}$ \\
\hline Alice & Não soube informar. & $\begin{array}{l}\text { Realizado com base nos objetivos de pesquisa do } \\
\text { projeto amplo do laboratório, buscando contemplar } \\
\text { os projetos de pesquisa que seriam realizados no } \\
\text { mestrado e no doutorado dos alunos de pós- } \\
\text { graduação envolvidos, além de conciliar com a } \\
\text { ampliação dos benefícios do projeto para os } \\
\text { participantes. }\end{array}$ \\
\hline
\end{tabular}

Fonte: Elaborado a partir dos dados da pesquisa.

Por meio das falas dos mestres participantes deste estudo, é possível verificar a presença de alunos da pós-graduação em concomitância com graduandos extensionistas, profissionais e professores universitários, durante o planejamento, a execução e a supervisão das atividades oferecidas por meio dos projetos de extensão. Essa característica relacional demonstra um trabalho transdisciplinar e intergeracional encontrado no cenário da universidade, local que facilita tal relação e busca fomentar a construção de saberes entre seus atores.

As mais variadas visões proporcionadas por cada membro do projeto de extensão, com diferentes pontos de vista e experiências prévias, podem contribuir para reflexões acerca do indivíduo que atuará na intervenção, por diferentes frentes, buscando atingi-lo de forma completa. Essa articulação entre o âmbito da pós-graduação e da graduação talvez represente um avanço mais acentuado nos últimos anos, pois, conforme ressaltava Cury (2004), a solidificação da pós-graduação nem sempre estava atrelada ao curso de graduação da própria universidade, nem mesmo visava colaborar para o aperfeiçoamento dessa etapa acadêmica inicial.

A contribuição da troca de saberes e experiências dos envolvidos para um determinado propósito pode ser verificada no estudo de Ramminger et al. (2014), o qual apresenta a criação de um grupo de pesquisa, fruto da experiência positiva com o projeto de extensão, devidamente cadastrado no Conselho Nacional de Desenvolvimento Científico e Tecnológico (CNPq), sendo composto por cinco professores, com diferentes projetos de pesquisa e intervenções, 15 alunos e duas trabalhadoras da rede pública de saúde, além de parcerias com outros grupos de pesquisa. Os autores caracterizam o grupo pela interação entre professores, alunos e trabalhadores na união de esforços para a criação de um campo de conhecimento comum, demonstrando o potencial dos trabalhos com diversos níveis acadêmicos e profissionais, bem como com variadas faixas etárias de seus integrantes, buscando proporcionar diversos desdobramentos relacionados ao objeto de estudo. 
A interação com outros alunos, pós-graduandos, professores e a comunidade, durante o processo de formação acadêmica, é possível ocorrer por meio de diferentes contextos. E os projetos de extensão representam um deles, podendo oportunizar diferentes benefícios aos envolvidos.

\section{Pontes entre extensão e pós-graduação}

Os investigados relataram os principais benefícios do trabalho concomitante com pesquisa e extensão, tais como: facilidades de acesso aos participantes para o estudo (3); apropriação do laboratório para o desenvolvimento de pesquisas científicas (2); envolvimento diário com o problema de pesquisa (1); observação na prática dos resultados do estudo (1); link entre a teoria e a prática (1); trabalho realizado em grupo (1); retorno à sociedade por meio das ações propostas (1); conhecimento prático do tema de estudo (1); ampliação dos tipos de estudos realizados, no caso, com a proposta de intervenção (1). O relato de Pedro é ilustrativo: "Apesar de o mestrado ser voltado à pesquisa, vejo na extensão uma ótima oportunidade para se manter inserido em um ambiente prático de trabalho. Sendo assim, há mais possibilidade ao sair do mestrado".

Benefícios semelhantes a esses também podem ser visualizados no estudo de Ramminger et al. (2014), realizado no nível da graduação, ao se estreitarem os laços da extensão com a pesquisa e o ensino. Os autores destacam alguns benefícios referentes a esse estreitamento de relações, tais como: a aprendizagem compartilhada, ao envolver professores, alunos e comunidade em problemas reais que ocorrem no cotidiano e na troca de saberes; o engajamento desses atores em todo o processo, desde o planejamento até o desenvolvimento e a elaboração de relatórios; e a contribuição para os projetos de pesquisa, por meio do aprofundamento de temáticas específicas, assim como de conceitos e concepções. Sendo assim, ao envolver outros níveis de formação, a exemplo da pós-graduação, espera-se ampliar tais benefícios.

Na perspectiva dos investigados, os projetos de extensão também favorecem a obtenção da amostra para a coleta de dados em pesquisas de pós-graduação. Além disso, foi exposto que os benefícios das intervenções extensionistas transcendem a pós-graduação, contemplando o ensino da graduação, o que contribui para a consolidação do tripé acadêmico, ao colaborarem para uma aprendizagem dinâmica e facilitada, na qual os orientadores, os professores da respectiva universidade, expõem, durante as aulas teóricas, situações reais, vivenciadas. Outros elementos elencados versam sobre a possibilidade de visualização dos resultados da pesquisa na prática, o melhor controle desses resultados, bem como a percepção de melhorias dos participantes a partir das intervenções propostas no projeto de pesquisa, possibilitando, concomitantemente, avaliar o projeto de extensão como um todo. Ainda, foi enfatizado o aspecto referente aos participantes envolvidos nas ações de extensão, com vistas a despertar o interesse deles para o meio acadêmico e a aprimorar constantemente as intervencões que realizam na extensao. Por fim, foi destacada a viabilidade da originalidade das pesquisas. 
Referente ao estreitamento entre a graduação e a pós-graduação, Cury (2004) destaca quão profícuos os resultados podem ser, em via de mão dupla. Uma vez realizadas as melhorias na graduação e feitos os entrelaçamentos com a pós-graduação, há maior tendência em aumentar o desempenho dos alunos formados, garantindo uma profissionalização de boa qualidade; ao mesmo tempo, isso poderia contribuir com futuros estudantes mais preparados para o envolvimento e a atuação, de modo qualitativo e dinâmico, na pós-graduação (CURY, 2004), assim como foi ressaltado pelos participantes desta presente pesquisa. Esses aspectos poderão refletir, inclusive, em um engajamento mais eficaz na extensão, caso o futuro mestrando se interesse, devido à sua bagagem formativa de excelência.

Embora possam ser observados vários benefícios advindos dos projetos de extensão, aqui traçados pelos mestres investigados, Arruda et al. (2015) destacam o desafio enfrentado pelos professores, os quais precisam despertar nos alunos a visão de que a universidade pode e deve contribuir para a sociedade, em congruência com o desenvolvimento de novas e atraentes estratégias de ensino, assim como com diferentes situações de aprendizagens, a fim de construir o conhecimento científico. Nessa premissa, espera-se promover um diálogo permanente entre os três segmentos: alunos, professores e sociedade, valorizando e aproximando a participação discente.

$\mathrm{Na}$ presente pesquisa, observa-se uma representativa aproximação dos mestres com as diversas tarefas dos projetos de extensão, assim como o reconhecimento das facilidades desse envolvimento. Nessa premissa, é possível afirmar que a relação ensino-pesquisa-extensão deve ser mais fomentada, tendo em vista as possíveis contribuições de cada pilar e o alcance dos objetivos formativos.

Ao focalizar a perspectiva oposta, ou seja, os possíveis benefícios dos estudos da pósgraduação para o universo da extensão, quando interligados, Tiago traz o seguinte olhar: "Espera-se que os pós-graduandos sejam pessoas que estão atualizadas com o que há de melhor no contexto científico, sendo assim, oferecendo o que se tem de mais atual em todas as áreas de estudo". Esse aspecto elencado por Tiago também foi evidenciado por Vanessa.

Nessa mesma direção, Sacardo e Hayashi (2011) apregoam que os pesquisadores, ao se engajarem no meio científico, estabelecem uma responsabilidade com o fazer ciência, de modo a contribuir para o avanço da área de conhecimento, assim como para a sociedade envolvida. Como resposta à colaboração da comunidade, espera-se que os pesquisadores lhe ofereçam retorno por meio das descobertas obtidas nas pesquisas e nos experimentos, compartilhando as experiências e os saberes.

Entretanto, não basta apenas os mestrandos estarem amparados pelo senso crítico e atualizados em relação à realidade científica para que de fato a extensão universitária seja construída e consolidada, é preciso ainda que a comunidade reconheça o espaço universitário também como um local de pensamento crítico da sociedade como um todo, de modo a se sentir parte desta e estabelecer com ela um constante diálogo, ou seja, influenciando e por ela sendo influenciada. Nesse sentido, a extensão deixará de ser meramente assistencialista (RODRIGUES, 2006), como, infelizmente, ocorre corriqueiramente. 
Outros benefícios apontados pelos mestres investigados referem-se ao fato de os resultados das pesquisas e os conhecimentos científicos poderem ser extrapolados diretamente para a prática, possibilitando uma modificação e um aprimoramento das propostas dos projetos de extensão e proporcionando a seus participantes intervenções qualificadas. A testagem do projeto e a aplicabilidade in loco das pesquisas também foram aspectos citados. Nessa mesma perspectiva, Amanda afirma: "Quando os estudos e a extensão estão interligados, há um controle maior na execução e no cuidado do planejamento das atividades; ainda, a cada resultado de estudo, pode-se observar possiveis mudanças para beneficios dos alunos".

Tratando-se da relação dos projetos de extensão com a comunidade, Manchur, Suriani e Cunha (2013) salientam que são necessárias políticas internas e externas no âmbito da universidade, uma vez que essas ações não devem assumir as funções e as responsabilidades do governo. Contudo, Mussoi e Lenzi (2015) alertam para a necessidade de articulação entre a universidade e as políticas públicas, seja em âmbito municipal, estadual ou federal, o que os autores chamam de "processo multiautoral", no intuito de proporcionar melhor desenvolvimento e abrangência aos projetos de extensão.

Os investigados deste estudo ainda apontaram sugestões para o cenário extensão-pósgraduação, no sentido de sistematizar o melhor funcionamento dessa relação, tais como: a realização de pesquisas em todos os programas de extensão e a clara delimitação dos momentos destinados à participação nas ações de extensão e nas atividades de pesquisa, a fim de garantir melhor aproveitamento de ambos os envolvimentos. Também foi sugerida uma disciplina, no currículo acadêmico, que ensine os alunos a criarem e planejarem um projeto de extensão, tendo em vista que este já existe ou parte sempre da iniciativa do professor, mas não do aluno.

Conforme proposto por Moita e Andrade (2009), uma estratégia possível, buscando aproximar os pilares da universidade, é a promoção de tal aproximação durante o período de estágio de docência dos alunos de pós-graduação. Corroborando o pensamento anteriormente exposto, Veiga (2006) acredita que a docência universitária exige a indissociabilidade entre os pilares ensino-pesquisaextensão, o que contribui para a atividade reflexiva e problematizadora do futuro professor universitário. A autora ressalta que a pesquisa e a extensão, indissociadas da docência, necessitam questionar o que se encontra fora do ângulo momentâneo de visão, o que não significa pensar na extensão como ações desmembradas, unicamente para uso externo, do que a universidade produzir de bom, mas propõe que o conhecimento científico produzido pela instituição deva servir para a melhoria das relações entre esse tripé acadêmico, bem como para sua capacidade de decisão, não se configurando como mera divulgação.

Ainda em relação às sugestões dos mestres investigados para uma melhor articulação entre a extensão e a pós-graduação, foram propostas parcerias com instituições que atendam ao mesmo público, a fim de facilitar o encaminhamento de pacientes, bem como uma maior integração entre as equipes para a cooperação. Ademais, foi citado que, embora a pós-graduação se relacione com a extensão, as burocracias existentes na universidade apresentam entraves para aumentar a proximidade entre esses dois 
pilares, o que deveria ser minimizado. Por fim, um dos mestres investigados não apontou sugestões quanto a essa relação.

Uma dessas burocracias, relatada por um dos participantes do presente estudo, refere-se às dificuldades financeiras. Contudo, mesmo enfrentando-as, as universidades públicas, em geral, vêm tentando contornar os obstáculos e manter a excelência no ensino, o investimento na pesquisa e o desenvolvimento de projetos de extensão, buscando, ainda, articular estes dois últimos, no intuito de manter o tripé acadêmico (CURY, 2004; MINTO, 2018). Ao focalizar o cenário atual brasileiro, com o aumento de cortes orçamentários e a falta de recursos financeiros suficientes para as instituições públicas de ensino, Minto (2018) afirma que o desafio de manter esse tripé ativo se torna cada vez mais robusto. Ademais, Minto (2018) critica esse aspecto como justificativa para a cobrança de mensalidades das pessoas, para que estas possam participar das atividades de extensão, o que pode prejudicar a acessibilidade da sociedade em geral à universidade, sendo essa uma das premissas da extensão, foco aqui discutido.

Nesse sentido, esperam-se mais auxílios e parcerias governamentais, os quais, aliados ao que há de mais recente e inovador nas pesquisas, com a aplicabilidade dos projetos em desenvolvimento, buscarão proporcionar à sociedade benefícios, a fim de se estender a outras populações, sem isentar, de fato, as responsabilidades destinadas às políticas públicas, mas promovendo ações de maneira conjunta, articulada e dinâmica.

\section{CONSIDERAÇÕES FINAIS}

Este estudo teve como objetivo investigar a participação de estudantes de pós-graduação em Educação Física em projetos de extensão e o reflexo disso na construção de suas dissertações. Nessa perspectiva, evidenciou-se o engajamento dos mestres investigados em projetos de extensão desde a graduação, o qual representa um dos motivos para a continuidade desse envolvimento durante a pósgraduação, de modo a influenciar, inclusive, a escolha pela elaboração da dissertação atrelada ao universo extensionista. Outros motivos, como o retorno social e a facilidade de obtenção de participantes para a coleta de dados, também foram elencados como opção para esse engajamento, no intuito de contribuir para a produção científica com o público alvo. Ademais, durante o envolvimento em projetos de extensão, abrem-se possibilidades para o aluno entrar em contato com diferentes contextos, com realidades transdisciplinares e intergeracionais, em que as responsabilidades aumentam, conforme o nível de formação acadêmica.

Relacionados a esses desdobramentos, foi possível identificar os benefícios da ponte entre a pós-graduação e a extensão em ambos os sentidos. Inclusive, as pesquisas advindas desse cenário podem proporcionar uma retroalimentação, no intuito de aprimorar as ações, garantido intervenções qualificadas à comunidade como um todo. Contudo, esses benefícios transcendem os pilares extensão e pesquisa, no 
que se pode notar, conforme a visão dos mestres investigados, o alcance do ensino por meio da ligação entre teoria e prática, possibilitado pelo compartilhamento de saberes e de uma aprendizagem dinâmica e constantemente atualizada.

Tal conexão é vislumbrada pelos mestres ao afirmarem que seus orientadores, durante as aulas da graduação, estabelecem a associação dos três pilares da universidade: ensino, pesquisa e extensão. Como sugestões para que essa relação seja fortalecida, destaca-se, por intermédio das falas dos participantes desta pesquisa, a necessidade de todos os projetos de extensão terem a eles a pesquisa atrelada, assim como a atenuação dos entraves burocráticos existentes no contexto universitário, aspectos capazes de facilitar a articulação e a contribuição equilibrada dessa tríade.

Como limitação deste estudo, aponta-se a necessidade de um número maior de investigados envolvidos no cenário da pós-graduação em concomitância com os projetos de extensão, inseridos em distintas áreas do conhecimento, e também de envolver outras universidades, a fim de propiciar diversos olhares e realidades sobre esse contexto. Espera-se que esta pesquisa possa despertar o ensejo do aprofundamento dessa perspectiva na pós-graduação, uma vez que suas contribuições são naturalmente debatidas no âmbito da graduação.

\section{REFERÊNCIAS}

ANJOS, F. F. M.; CARIO, S. A. F.; FIATES, G. G. S. Avaliação da estrutura de governança do arranjo produtivo de software da região da Grande Florianópolis - Estado de Santa Catarina, Brasil. Revista Pymes, Innovación y Desarrollo, Santa Fé, v. 2, n. 3, p. 30-53, 2014. Disponível em: https://revistas.psi.unc.edu.ar/index.php/pid/article/view/11504. Acesso em: 5 nov. 2016.

ARRUDA, A. P. D. et al. A aplicação da metodologia da problematização em projeto de extensão: um relato de experiência em uma comunidade cigana. Revista Docência no Ensino Superior, Belo Horizonte, v. 5, n. 1, p. 113-134, abr. 2015. DOI: https://doi.org/10.35699/1981-3171.2008.914. Disponível em: https://seer.ufmg.br/index.php/rdes/article/view/914. Acesso em: 16 nov. 2016.

BARDIN, L. Análise de conteúdo. Ed. Rev. Actual. Lisboa: Edições 70, 2009.

BARRAGÁN, T. O. et al. O papel da extensão universitária e sua contribuição para a formação acadêmica sobre as atividades circenses. Pensar a Prática, Goiânia, v. 19, n. 1, p. 42-55, jan./mar. 2016. DOI: https://doi.org/10.5216/rpp.v19i1.35857. Disponível em: https://www.revistas.ufg.br/fef/article/view/35857. Acesso em: 16 nov. 2016.

BRASIL. Ministério da Educação. I Encontro de pró-reitores de extensão das universidades públicas brasileiras. Brasília, 1987. Disponível em: https://www.ufmg.br/proex/renex/images/documentos/1987-I-Encontro-Nacional-doFORPROEX.pdf. Acesso em: 19 nov. 2016.

BRASIL. Lei n ${ }^{\circ}$ 9.394, de 20 de dezembro de 1996. Estabelece as diretrizes e bases da educação nacional. Brasília, DF: Presidência da República, [2018]. Disponível em: http://www.planalto.gov.br/ccivil_03/leis/19394.htm. Acesso em: 14 maio 2019. 
CIRANI, C. B. S.; CAMPANARIO, M. A.; SILVA, H. H. M. A evolução do ensino da pós-graduação senso estrito no Brasil: análise exploratória e proposições para pesquisa. Avaliação, Campinas; Sorocaba, v. 20, n. 1, p. 163-187, mar. 2015. DOI: http://dx.doi.org/10.590/S141440772015000500011. Disponível em: http://www.scielo.br/pdf/aval/v20n1/1414-4077-aval-20-0100163.pdf. Acesso em: 13 nov. 2016.

\section{CONSELHO FEDERAL DE EDUCAÇÃO. Parecer nº 977/65. Definição dos cursos de pós- graduação. Brasília, DF: 1965.}

CRESTANI, M. M. et al. Bolsista de um projeto de extensão: relato de experiência. Extensio: Revista Eletrônica de Extensão, Florianópolis, v. 1, n. 1, p. 1-5, jan. 2004. Disponível em: https://periodicos.ufsc.br/index.php/extensio/article/view/1171/4369. Acesso em: 25 nov. 2016.

CURY, C. R. J. Graduação/pós-graduação: a busca de uma relação virtuosa. Educação \& Sociedade, Campinas, v. 25, n. 88, p. 777-793, out. 2004. DOI: http://dx.doi.org/10.1590/S0101-

73302004000300007. Disponível em: https://www.scielo.br/scielo.php?script=sci_arttext\&pid=S0101$73302004000300007 \& \operatorname{lng}=$ pt\&tlng=pt. Acesso em: 16 nov. 2016.

FERNANDES, M. C. et al. Universidade e a extensão universitária: a visão dos moradores das comunidades circunvizinhas. Educação em Revista, Belo Horizonte, v. 28, n. 4, p. 169-194, dez. 2012. DOI: http://dx.doi.org/10.1590/S0102-46982012000400007. Disponível em:

https://www.scielo.br/scielo.php?script=sci_arttext\&pid=S0102-

46982012000400007\&lng=pt\&tlng=pt. Acesso em: 16 nov. 2016.

FERREIRA, M. A. G.; SANCHES, S. P. Mobilidade cicloviária em Campus Universitário. In: CONGRESSO BRASILEIRO DE TRÂNSITO E TRANSPORTE, 19., 2013, Brasília. Anais [...]. Brasília, 2013. p. 1-9. Disponível em: http:// filesserver.antp.org.br/_5dotSystem/download/dcmDocument/2013/10/07/28D38498-1148-42CD8920-4FA2C010CA69.pdf. Acesso em: 5 nov. 2016.

HECK, T. G. et al. Iniciação científica no ensino médio: um modelo de aproximação da escola com a universidade por meio do método científico. Revista Brasileira de Pós-Graduação, Brasília, v. 8, n. 2, p. 447-465, mar. 2012. DOI: https://doi.org/10.21713/2358-2332.2012.v8.245. Disponível em: http://ojs.rbpg.capes.gov.br/index.php/rbpg/article/view/245. Acesso em: 16 nov. 2016.

HIRANA, L. K. et al. Extensão universitária e formação do professor de educação física: contribuições a partir da permanência prolongada. Revista Ciência em Extensão, São Paulo, v. 12, n. 1, p. 28-40, 2016. Disponível em: https://ojs.unesp.br/index.php/revista_proex/article/view/1125. Acesso em: 19 jun. 2020.

KOCHHANN, A. Formação de professores na extensão universitária: uma análise das perspectivas e limites. Teias, Rio de Janeiro, v. 18, n. 51, p. 276-292, out./dez. 2017. DOI: 10.12957/teias.2017.29206.

KREMER, N. S.; WELTER, T.; GROSSI, M. P. Trajetórias e experiências no Ensino Médio: a extensão universitária criando possibilidades. Caminho Aberto: Revista de Extensão do IFSC, Florianópolis, v. 1, n. 1, p. 83-89, 2014. Disponível em: http://miriamgrossi.paginas.ufsc.br/files/2012/03/Visualizar30.pdf. Acesso em: 16 nov. 2016.

LIMA, L. F. Contribuições dos projetos de extensão na ação profissional dos professores universitários. Pesquisa em Foco, São Luís, v. 20, n. 2, p. 47-65, 2015. Disponível em: http://ppg.revistas.uema.br/index.php/PESQUISA_EM_FOCO/article/view/1012/795. Acesso em: 19 jun. 2020. 
MACHADO, L. R. S.; SANTOS, E. H.; QUARESMA, A. G. Cursos de mestrados no Brasil, na França e em Portugal: elementos de uma abordagem comparativa. Revista Brasileira de Pós-Graduação, Brasília, v. 11, n. 26, p. 939-964, dez. 2014. DOI: https://doi.org/10.21713/2358-2332.2014.v11.556. Disponível em: http://ojs.rbpg.capes.gov.br/index.php/rbpg/article/view/556. Acesso em: 16 nov. 2016.

MANCHUR, J.; SURIANI, A. L. A.; CUNHA, M. C. A contribuição de projetos de extensão na formação profissional de graduandos de licenciaturas. Revista Conexão UEPG, Ponta Grossa, v. 9, n. 2, p. 334-341, jul./dez. 2013. Disponível em:

https://revistas2.uepg.br/index.php/conexao/article/view/5522/3672. Acesso em: 7 nov. 2016.

MAZO, G. Z. et al. Grupo de Estudos da Terceira Idade-GETI: uma proposta de integração entre extensão, ensino e pesquisa voltados à pessoa idosa. Revista Conexão UEPG, v. 9, n. 1, p. 94-105, jan./jun. 2013. Disponível em: https://revistas2.uepg.br/index.php/conexao/article/view/5291/3400. Acesso em: 17 nov. 2016.

MINTO, L. W. Gratuidade do ensino superior em estabelecimentos oficiais: precisão e implicações. Educação \& Sociedade, Campinas, v. 39, n.142, p. 153-170, jan./mar. 2018. DOI:

http://dx.doi.org/10.1590/es0101-73302018181580. Disponível em: https://www.scielo.br/scielo.php?script=sci_arttext\&pid=S0101 73302018000100153\&lng=pt\&tlng=pt. Acesso em: 19 jun. 2020.

MOITA, F. M. G. S. C.; ANDRADE, F. C. B. Ensino-pesquisa-extensão: um exercício de indissociabilidade na pós-graduação. Revista Brasileira de Educação, Rio de Janeiro, v. 14, n. 41, p. 269-280, maio/ago. 2009. DOI: https://doi.org/10.1590/S1413-24782009000200006. Disponível em: http://www.scielo.br/scielo.php?pid=S1413-24782009000200006\&script=sci_abstract\&tlng=pt. Acesso em: 22 nov. 2016.

MOREIRA, M. A. O mestrado (profissional) em ensino. Revista Brasileira de Pós-Graduação, Brasília, v. 1, n. 1, p. 131-142, jul. 2004. DOI: https://doi.org/10.21713/2358-2332.2004.v1.26. Disponível em: http://ojs.rbpg.capes.gov.br/index.php/rbpg/article/view/26. Acesso em: 19 nov. 2016.

MUSSOI; E. M.; LENZI. L. H. C. Extensão universitária: entre o continuismo e a utopia. Extensio: Revista Eletrônica de Extensão, Florianópolis, v. 12, n. 20, p.103-122, dez. 2015. DOI: http://dx.doi.org/10.5007/1807-0221.2015v12n20p103. Disponível em: https://periodicos.ufsc.br/index.php/extensio/article/view/1807-0221.2015v12n20p103/30939. Acesso em: 25 nov. 2016.

NOGUEIRA, M. A.; CANAAN, M. G. Os “iniciados”: os bolsistas de iniciação científica e suas trajetórias acadêmicas. Revista do Programa de Pós-Graduação em Sociologia, São Cristóvão, n. 15, p. 41-70, jul./dez. 2009. DOI: https://doi.org/10.21669/tomo.v0i15.488. Disponível em: https://seer.ufs.br/index.php/tomo/article/view/488. Acesso em: 19 nov. 2016.

RAMMINGER, T. et al. A indissociabilidade entre ensino, pesquisa e extensão: um relato de experiência da integração entre a Universidade e a rede de atenção integral à saúde mental em Volta Redonda-RJ. Revista Pesquisas e Práticas Psicossociais, São João del-Rei, v. 9, n. 1, p. 97-105, jan./jun. 2014. Disponível em: http://www.seer.ufsj.edu.br/index.php/revista_ppp/article/view/836. Acesso em: 22 nov. 2016.

RAMOS, G. et al. Egressos do curso de educação física da Universidade Federal de São Carlos (19972003): formação e atuação. Movimento e Percepção, Espírito Santo do Pinhal, v. 9, n. 13, p. 249-265, jan. 2008. Disponível em: 
http:// ferramentas.unipinhal.edu.br/movimentoepercepcao/viewarticle.php?id=19. Acesso em: 16 nov. 2016.

RODRIGUES, R. A extensão universitária como uma práxis. Extensão, Uberlândia, v. 5, p. 84-88, 2006. Disponível em: http://www.seer.ufu.br/index.php/revextensao/article/view/20340/10820. Acesso em: 21 nov. 2016.

RODRIGUES, A. A. L. et al. Contribuições da extensão universitária na sociedade. Cadernos de Graduação - Ciências Humanas e Sociais, Aracaju, v. 1, n. 16, p. 141-148, mar. 2013. Disponível em: https://periodicos.set.edu.br/index.php/cadernohumanas/article/viewFile/494/254. Acesso em: 19 jun. 2020.

SACARDO, M. S.; HAYASHI, M. C. P. I. Balanço bibliométrico da produção científica em Educação Física e Educação Especial oriunda de teses e dissertações. Revista Brasileira de Pós-Graduação, Brasilia, v. 8, n. 15, p. 111-135, mar. 2011. DOI: https://doi.org/10.21713/2358-2332.2011.v8.212. Disponível em: http://ojs.rbpg.capes.gov.br/index.php/rbpg/article/view/212. Acesso em: 16 nov. 2016.

SALLES, W. N.; FARIAS, G. O.; NASCIMENTO, J. V. Inserção profissional e formação continuada de egressos de cursos de graduação em Educação Física. Revista Brasileira de Educação Física e Esporte, São Paulo, v. 29, n. 3, p. 475-486, jul./set. 2015. DOI: https://doi.org/10.1590/180755092015000300475. Disponível em: http://www.revistas.usp.br/rbefe/article/view/105823. Acesso em: 17 nov. 2016.

VEIGA, I. P. A. Docência universitária na educação superior. In: RISTOFF, D.; SEVEGNANI, P. (org.). Docência na educação superior. Brasília, DF: INEP, 2006.

VIVIURKA, A. B; PORTO ALEGRE, L. M. O retrato da extensão universitária pelos docentes. Revista Conexão, Ponta Grossa, v. 9, n. 1, p. 58-69, jan./jun. 2013. Disponível em: https://revistas2.uepg.br/index.php/conexao/article/view/4947/3398. Acesso em: 17 nov. 2016. 